\title{
An Overview on Post Harvest Handling and Commercial Processing of Horticultural Crops in NEH region of India
}

\author{
Md Manzar Hossain \\ Central Institute of Horticulture,Dept. of Agriculture and Co-operation, Ministry of Agriculture, Government of India, Medziphema, \\ Nagaland-797106
}

\begin{abstract}
North east region is blessed with diverse agro climatic conditions which are suitable for cultivation of various horticultural crops. The main horticultural crops grown in this region are aonla, banana, guava, jackfruit, khasi mandarin, mango, pineapple, peach, pear, plum, passion fruit, kiwi, beans, brinjal, cabbage, cauliflower, chow chow, cucumber, tomato, turmeric, ginger, king chilli, large cardamom and black pepper. The NEH region produces 11,637,980.00 MT fruits and vegetables. Due to difficult terrain, poor transportation facilities and unavailability of refrigerated vehicle leads to the severe post harvest loss of horticultural crops. In spite of lack of various post harvest handling facilities fewer innovative techniques have been developed for extending the shelf life of fruits and commercialized such as waxing, packaging in perforated poly bags and corrugated fiber boxes, modified atmosphere storage and control atmosphere storage supplemented with cold temperature. Surprisingly the NEH region has 53 numbers of cold storage with value capacity of 130,376 MT. Most of the processed product of fruits, vegetables and spices are prepared in cottage or small scale sector and usually operated by women. The growth potential of this sector is enormous in this region even though there are still some significant constraints which, if not addressed sooner, can impede the growth prospects of the Food Processing Industry in NEH region. Special attention is required to develop the infrastructure facilities with financial support by the government of India and there is also need to generate the awareness among the farming communities in this region to promote this sector on national and global level.
\end{abstract}

Keyword: Horticulture, Food processing, Value addition, PHT, NEH

\section{Introduction}

The North-Eastern Himalayan region of India, comprising the states of Arunachal Pradesh, Assam, Manipur, Meghalaya, Mizoram, Nagaland, Sikkim and Tripura, lies between $21.5^{\circ} \mathrm{N}$ to $29.5^{\circ} \mathrm{N}$ latitude and $85.5^{\circ} \mathrm{E}$ to $97.5^{\circ} \mathrm{E}$ longitude [6]. It represents a distinct agro-climatic zone which varies from tropical to temperate and falls under high rainfall zone. The region is characterized by difficult terrain, wide variations in slopes, altitude, land tenure systems and diverse cultivation practices. The transport and communication system is poorly developed and as a result majority of the areas in the region remain still inaccessible. The infrastructure facilities like supply of input, post harvest facilities; marketing, institutional credit and extension services are inadequate. The total area under horticultural crops is around 1397 thousand hectares, which is around 5.46 percent of the total geographical area of the region. The area under various fruit crops in NEH region is 505.32 thousand hectares and production is 4780.89 thousand tons with average productivity 9.46 tons per hectare. The total area under vegetable crops in the NEH region is 525.76 thousand hectares and production is 5853.57 thousand tons with productivity of 11.13 tons per hectare [2]. The diverse climatic agro-conditions, varied soil type and abundance of rainfall offers huge potential for cultivation of different types of horticultural crops, including fruits, vegetables, flower, plantation crops, tuber crops, spices and medicinal and aromatic plants. The fruit grown in this region ranges from tropical and sub-tropical like banana, papaya, pineapple, jackfruit and citrus to temperate fruits like apple, pear, peach and plum. The region has rich diversity of various types of vegetable crops and both tropical and temperate vegetables are grown to a considerable extent.
The major vegetables grown in the region are brinjal, cabbage, cauliflower, okra, onion, pea, tomato, knoll-khol, radish, carrot, French bean and cucurbitaceous crops. Ginger and turmeric are well-established cash crops of this region while large cardamom is a major plantation crop in Sikkim and some parts of Nagaland. Among the NEH region Assam produces highest amount of spices followed by Meghalaya. The region has tremendous potential for the development of horticulture sector but due to high rainfall and high humidity persisting throughout the year is congenial for growth and development of micro-organism. The studies conducted by Deka et al (2004), reported that post harvest losses vary from 5 to $40 \%$ depending upon the crop, variety and weather condition [14]. The post harvest losses in case of banana have been recorded from $15-20 \%$, where as in case of pineapple, khasi mandarin and tomato are 12-17, 21-25 and $21-30 \%$ respectively. Therefore, it is necessary to identify the different types of problem faced by the grower during harvesting, storage, processing and value addition of horticultural crops in the NEH region. Our study is an attempt to highlight the various post harvest practices such as post harvest handling, food processing and suitable value added product for different horticultural crops in $\mathrm{NEH}$ region as a means to provide nutritional security and, to combat the hidden hunger as well as employment generation in the region. Due to its unique socio-economic and demographic features, the $\mathrm{NEH}$ region is different from other states of India, and for its development, the government has come out with special policies.

\section{Post Harvest Handling in NEH Region}

To minimize post harvest loss the correct stage of maturity of fruit is very important specially at harvesting time. This 


\section{International Journal of Science and Research (IJSR) \\ ISSN (Online): 2319-7064 \\ Index Copernicus Value (2013): 6.14 | Impact Factor (2014): 5.611}

maturity is indicated by several parameters based on visual, physical and chemical indices. These not only help in deciding the date of harvest but also to sort out the harvested fruits into lots of varying maturity for their optimum use. Studies conducted at ICAR Research Complex for NEH region, Umiam shows that Khasi mandarin harvested during November can successfully be stored for 45 days. In NorthEast Himalayan region of India, the harvesting of fruits is still done manually. Oranges are normally harvested by hand-picking or by climbing on the trees directly or with the help of indigenously developed bamboo ladder (Fig. 1.a) or sometimes directly by beating the branches with long bamboo stick. Pineapple and banana are generally harvested by a sharp sickle-shaped hand tool locally known as ,Dao ${ }^{\text {ee }}$ where as tuber and rhizomatous crops are harvested mainly with the help of spade. The vegetables like tomato, capsicum, cucurbits and cole crops are harvested manually. The techniques for harvesting of banana, citrus, grape, papaya and pineapple are available elsewhere in the country. But no such techniques have been standardized for harvesting of Khasi mandarin, indigenous varieties of banana and pineapple in this region.

The most of the horticultural produce like citrus, banana, pineapple, tomato, capsicum, king chilli and bean are collected in bamboo baskets locally called as ,Khang ${ }^{\text {ee }}$ (Fig.2.a) in Nagaland, while harvesting or plucking, therefore produce does not come in contact with soil and its quality is better. ICAR Research Complex for NEH Region, Barapani, has developed a harvester, which can harvest fruits with pedicel of 1 to $2 \mathrm{~cm}$. in length. This stops sap bleeding and reduces latent infection and increases shelf-life of fruits by 2 to 4 days. The collections of fruits are done manually in indigenous manufactured bamboo basket and assembled these produce near the farm mostly in open sun condition (Fig 1. b). Grading of horticultural crops is not prevalent in this region due to unavailability of packhouse facilities near the farm and existing market. However, certain fruits and vegetables like pineapple, orange, guava, banana, cucurbit, tuber crops, tomato and capsicum are sold as per their size in different grades. The grading is done through visual perception of colour, uniformity in size, shape, consistency and texture. In local markets mandarins are normally packed in $20-25 \mathrm{~kg}$ capacity bamboo baskets truck (Fig. 1. c) while plums are packed in 5-10 kg bamboo basket and transported through pickup truck (Fig. 2. b) or tempo without giving any cushioning material or pad in the floor of vehicle. Bamboo baskets are generally square, cylindrical or conical in shape and fruits or vegetables are kept in different layers with paddy-straw or plant-leaves at the bottom and top, which provides as cushioning material. These fruits are re-packed in wooden boxes, which contain 5 and $10 \mathrm{~kg}$ fruits for sending outside the region. The shelf-life or Khasi mandarin fruit increased upto 45 days when packed in poly sheet (50 gauge) and stored at room temperature $\left(20 \pm 2^{0} \mathrm{C}\right)$. Similarly in case of corrugated fiber board (5 ply) the shelf-life increased up to 21 days by using newspaper cuttings as cushioning material. Pineapple is also usually carried in conical or square/ rectangular shaped bamboo baskets [7] (Fig. 2.a) containing 20-25 fruits and carried manually to the roadside or collection centre. Peach and plum are brought from the farmeres fields in bamboo baskets and repacked in small cartons of 2-5 kg. Due to the absence of suitable packaging material and being highly perishable, plums and peaches are not transported to distant markets. ICAR Research Complex, Barapani has standardized different packaging materials for important fruits and vegetables. The capsicum and brinjal were stored for 16 and 18 days respectively in perforated PET (polyethylene Terephthalate) film of 150 gauge).The shelf-life of fruits and vegetables could be doubled under normal conditions of storage by pre-packaging them in appropriate packages with adequate ventilation by controlling physiological changes and mechanical damage.

The NEH region is rich in forest vegetation and their products or by-products such as bamboo, cane, pine needle and sawdust, which are locally available; these can be utilized for preparation of cheap, cost-effective and ecofriendly packaging material. The storage of orange and pineapple is done in temporary huts prepared near the house made of locally available material. In the hut, racks are made and it is covered with straw or plant leaves to avoid exposure of fruits to the atmosphere, where as pineapple is kept without making layers. By this method oranges and pineapples are stored for about 20-30 days and 7-10 days respectively without any damage and farmers sell them according to their need and demand from the market. On the other hand, storage of ginger and turmeric is done in the dugout pits. First of all a pit is dug as per the quantity of produce to be stored. At the bottom of the pit, a layer of grass or paddy-straw is laid and on this ginger or turmeric is kept horizontally in different layers. Finally at the top, the pit is covered and plastered with soil. While removing the rhizome, only one side of the pit is opened and after taking out the required quantity, the opening is filled with soil to avoid exposure of rhizomes to the atmosphere. This method is followed in almost every part of the ginger and turmeric growing areas. Produce is kept fresh for about 4-5 months, generally from November to March [1].

\section{Post harvest Infrastructure and Food Processing Industries in NEH Region}

The food processing industry in this region is mainly unorganized and works on a smaller scale. Own-account enterprises hold the highest share in the unorganized sector [3] and the latest estimated number of registered and unregistered food processing industries under Ministry of Food Processing are 1,333 and 102,263 respectively [5]. The huge presence of the unorganized sector can be attributed to the fact that most of the units in the unorganized sector are less capital intensive, and the easy availability of raw materials makes it more attractive to the small entrepreneurs for seasonal processing. The high presence of own account enterprises does serve to mitigate unemployment to a large extent, but this sector is also responsible for the low level of income generation, and low level of productivity in the region. Among all the sectors in food processing industry, the sector which has an advantage in NEH region over the rest of India is the horticulture industry. The northeast Himalayan region has observed high production of fruits, vegetables and spices in the recent past but could not fetch market prices that are on par with markets in other states. The surplus produce often spoils and is wasted due to lack of transportation, inadequate number of cold storage facilities

\section{Volume 4 Issue 11, November 2015}




\section{International Journal of Science and Research (IJSR) \\ ISSN (Online): 2319-7064}

Index Copernicus Value (2013): 6.14 | Impact Factor (2014): 5.611

and processing of farm produce. Due to transportation and marketing difficulties, processing of fruits and vegetables may be an alternative sector through which a reasonable return can be ensured to the growers. Most of the fruits and vegetables are sold as fresh and less than two percent of the total production is being processed for other value-added products like jam, jelly, squash, sauce, pickle, dehydrated product and wine. There are about 53 cold storage facilities [4] and 112 processing units [8] spread throughout the region and among the region, the highest number of cold storage and processing unit is located in Assam it shares more than $55 \%$ of the region and Arunachal Pradesh has least number of processing unit. Most of these units are involved in processing pineapple and citrus with negligible amount of guava and other fruits and vegetables. Certain units like M/s. Fruitos and Company, Guwahati, process some vegetables in lean season. However, all the units suffer heavy losses every year mainly due to the absence of sales promotion, sales organized at individual level, inefficient production process, poor management system, high overhead cost, non-utilization of byproducts. The processing industry for extraction of oil from fresh ginger has been established recently in two states i.e. Manipur and Meghalaya to process the surplus ginger from this region [1].

\section{Value addition of horticultural crops in NEH region}

Horticulture is concerned with perishable crops such as fruits and vegetables which can be preserved for longer duration by using suitable food processing techniques. Therefore, it is necessary to develop the processing industry along with the development of horticulture, otherwise it will be uneconomical. In recent year the produce and then sell mentality of the commodity business is being replaced by the strategy of first determining what attributes consumers want in their food products and then creating or manufacturing products with those attributes. With the continuous shifting to a global economy, the international market for value-added products is growing. Producers have a challenge to be responsive to consumer demands by producing what is desired. Attentiveness to consumer demands in quality, variety and packaging are important, because demographic trends show growth in the convenience-oriented, health-conscious and environmentally concerned sectors where price is not as important as quality. Because value-added research is important, producers might examine competitive advantages obtainable with processed products compared to raw commodities. The selected horticultural cops present in $\mathrm{NEH}$ region and its major commercial application are given in table 1 .

\section{Constrains}

Growing urbanization, increasing disposable income, emergence of organized food retail, changing lifestyles, husband-wife working culture and food consumption patterns are the key factors in driving the growth for post harvest handling [9] and food processing in this region. In spite of this the major constraints of post harvest handling, food processing industry and value addition in $\mathrm{NEH}$ region are (1) lack of contact farming system to ensure uniform supply of raw material, (2) lack of skilled manpower, (3) Inefficient utilization of processing unit as most of the units are non-functional throughout the year, (4) absence of adequate transportation facilities, (5) inadequate number of cold storage and processing facilities, (6) poor quality standards of produce and its control methods (7) high capital investment for establishment of processing unit and its operational cost (8) lack of multi fruits or vegetable processing unit (9) hidden tax by various underground groups (10) inadequately linkages between R\&D labs and industry (11) high cost of packaging material and poor marketing infrastructure and (12) finally the preference of the consumer.

\section{Future Thrust}

Considering the limited and dwindling land and water resources, slow growth in productivity and ever-increasing population, minimizing postharvest losses [10] is one of the most effective and economical ways of increasing per capita food availability. Postharvest and food technology has to be location specific. However, the present requirement is to develop need based and market-driven postharvest technology for loss prevention and generation of raw materials of horticultural origin. Postharvest losses could be substantially reduced by adopting improved equipment and processes for product development [11]. The following thrust areas identified in postharvest handling and food processing, which need immediate attention for employment generation and food security [12].

- Contract farming system to ensure uniform supply of raw material

- Survey of post harvest handling practices follows in the region

- Precision post harvest technologies using automation during post harvest handling

- Introduction of low cost bulk storage structure for horticulture produce at production and dispatch area.

- Development of complete Post harvest chain from farm to fork.

- Innovation in product development.

- Adoption of non-thermal and non-chemical processing and preservation of food products.

- Faster detection of adulterants and pesticides residue in processed products using biosensor/nano-sensor.

- Need for development of low cost packaging.

- Establishment of central processing hub $(\mathrm{CPH})$ or mobile food processing unit.

- Integration of vast domestic as well as international market.

- Government initiative based on post harvest infrastructure.

\section{Conclusion}

The NEH region is rich in different types of horticultural crops which may provide sufficient raw material for food processing industries through improved production technology and post harvest management, and often called as sun rise sector will be natural choice for investors. However, this sector has a huge scope for future growth. Various other sectors within the horticultural industries such 


\section{International Journal of Science and Research (IJSR) \\ ISSN (Online): 2319-7064 \\ Index Copernicus Value (2013): 6.14 | Impact Factor (2014): 5.611}

as post-harvest sector, nutraceutical, traditional foods and convenience foods are still in an infant stage, and this region has the potential to be a hot destination in those as well. It can boost economic growth by providing suitable post harvest practices and value addition techniques to the farmers and processors.

\section{References}

[1] Goel, K.L., Kumar, R. and Mann,S.S., Post harvest management and value addition, Daya Publishing House, New Delhi, Edition-2007.

[2] Final estimate of Area, Production and Productivity of Horticulture Crops, 2013-14, National Horticulture Board (NHB Data base 2015), www.nhb.gov.in

[3] http://www.nehu.ac.in/Journals/NEHUJournalJan_June 2014_Art3.pdf Accessed on 05.10.2014.

[4] Data base on cold storage: www.agmarknet.nic.in/asnew.htm browse on 06.10 .2014

[5] http://mofpi.nic.in/H Dwld.aspx?KYEwmOL+HGqTrh LeUJv1qkQ0u6ur0YH8bufgUbQ7I8nj7GdfDPc8oA=A ccessed on 06.10 .2014

[6] www.wikipedia.com, Geographical area of NER, India, Accessed on 10.10.2014.

[7] Hossain, M., and Bepary, R.H., 2015. Post Harvest Handling Of Pineapples: A Key Role To Minimize The Post Harvest Loss. International Journal of Recent Scientific Research, 6(9) pp.6069-6075.

[8] Data base on fruit and vegetable processing in NER: www.kiran.nic.in browse on 11.10.2014
[9] Batista, O. K., 1990. Postharvest technology for Southeast Asian perishable crops a simplified guide: a simplified guide, Publisher: Makati, Metro Manila, Philippines.

[10] Thompson, A.K., 2003. Fruits and vegetables, Harvesting, Handling and Storage. Publisher Blackwell publishing Ltd., UK. (9-31)

[11]Kader, A., and Siddiq, M., 2012. Introduction and Overview; Edited by Muhammad Siddiq; Tropical and Subtropical Fruits Postharvest Physiology, Processing and Packaging, published by John Wiley \& Sons, Inc. (1-16).

[12] Acharya, S. K., K. Pradhan , P. Choudhuri , and A. B. Sharangi, 2015. Introduction; Value Addition of Horticultural Crops: Recent Trends and Future Directions; Edited by Sharangi, Amit Baran, Datta, Suchand, Publisher: Springer (India) Pvt. Ltd. (1-12).

[13]Lozano, J.E., 2006. Fruit Manufacturing, Scientific Basis, Engineering Properties and Deteriorative Reactions of Technological Importance, Publisher; Springer, Science and Business Media, LLC.

[14] Deka, B. C., Sharma, S., Patgiri, P., Saikia, A. and Hazarika, C., 2004. Post harvest practices and loss assessment of some commercial horticultural crops of Assam. Indian Food Packer 58 (1): 85-87.

[15] Source of citrus photo: "Expert consultation meeting on citrus development in NER" on 25th June 2012 at Central Institute of Horticulture, Medziphema, Nagaland.

Table 1: List of horticultural crops suitable for commercial application $[12,13]$.

\begin{tabular}{|c|c|}
\hline \multicolumn{2}{|r|}{ Major commercial application } \\
\hline \multicolumn{2}{|r|}{ 1. Fruits } \\
\hline Apple & $\begin{array}{l}\text { Juice, Jam, jelly, cider, wine, pulp, osmotically dried rings, canned apple, vinegar, carbonated juice, apple } \\
\text { seed for nurseries, pectin, fibre from pomace }\end{array}$ \\
\hline Passion fruit & Squash, Juice, RTS, Jam, powder \\
\hline Plum & Pulp, squash/ appetizer, RTS, chutney, jam, wine/ brandy, plum sauce, seed oil \\
\hline Peach & Canned peach, pulp, jam/ chutney, wine, kernel oil \\
\hline Pear & Canned pear, pulp, jam, apple pear blend, sand pear candy, vermouth \\
\hline Pineapple & Jam, juice, squash, osmotically dried candy, RTS, canned pineapple slice \\
\hline Mango & $\begin{array}{l}\text { Pulp, RTS, squash, powder (amchur), slices in brine, pickle, pulp/ juice from in situ mangoes, pectin from } \\
\text { just-ripe fruits }\end{array}$ \\
\hline Grapes & Raisin, juice, carbonated juice/ RTS \\
\hline Litchi & Juice, squash, nectar/ RTS, carbonated drink \\
\hline \multicolumn{2}{|r|}{ 2. Vegetables } \\
\hline Cabbage & Dehydrated cabbage, Sauerkraut/fermented cabbage \\
\hline Cauliflower & Pickle, slices in brine, frozen cauliflower heads, left over for drying powder \\
\hline Carrot & Pickle, slices in brine, preserve, candy, freezing and drying, juice, canned and fermented carrot \\
\hline Cucumber & Pickle and gherkin \\
\hline Okra & Dehydrated okra, canned and frozen okra \\
\hline Onion & Dehydrated onion, pickle onion, Onion chopped, Onion Minced, Onion Granules and Onion Powder. \\
\hline Tomato & Juice, sauce, ketchup, paste, drying, powder \\
\hline Tapioca & Chips and powder \\
\hline \multicolumn{2}{|r|}{ 3. $\quad$ Spices } \\
\hline Chillies & Powder, pickles, paste, oleoresin, oil brined chilli, sauces \\
\hline Coriander & Powder, oleoresins \\
\hline Fenugreek & Powder, dried fenugreek leaves \\
\hline Ginger & Powder, wines, dry ginger, starch from spent ginger, preserves, gingiberin oil, oleoresin \\
\hline Garlic & Garlic powder, garlic paste, garlic oleoresin \\
\hline King chilli & Dehydrated product, pickle and paste. \\
\hline Turmeric & Natural pigments, curcuminoids, oleoresins \\
\hline
\end{tabular}




\section{International Journal of Science and Research (IJSR)}

ISSN (Online): 2319-7064

Index Copernicus Value (2013): 6.14 | Impact Factor (2014): 5.611

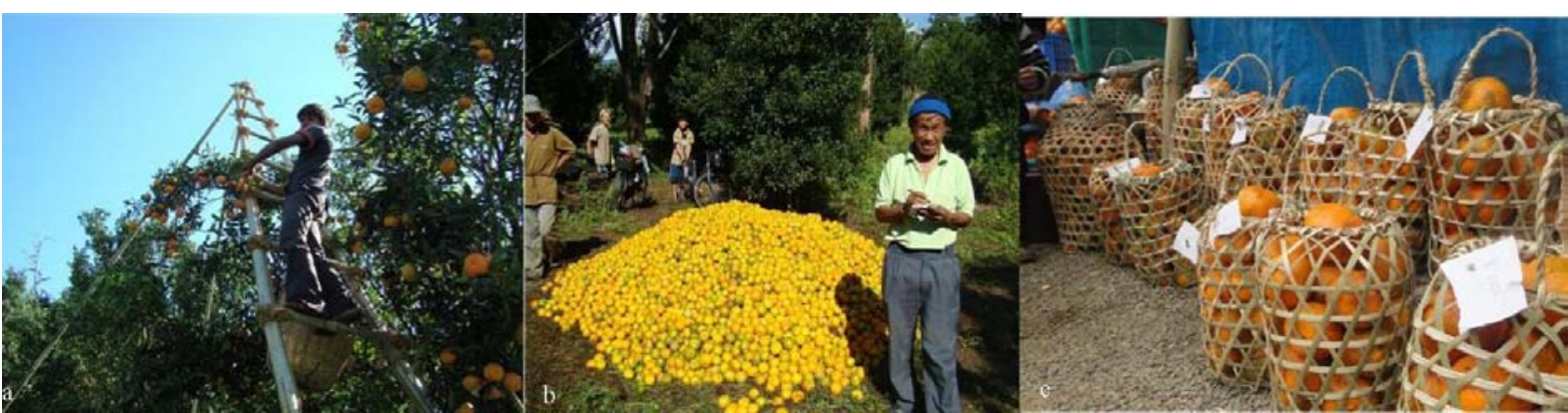

Figure 1: Citrus fruit [15] (a) Harvesting (b) Collection of fruit in the orchard (c) Packaging of fruit in bamboo basket.

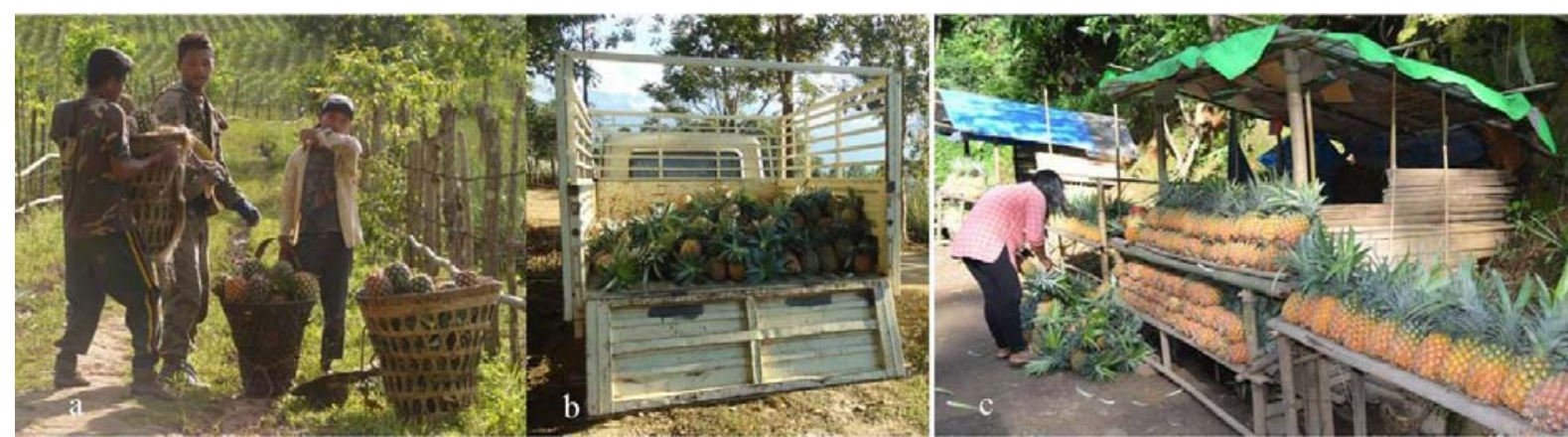

Figure 2: Pineapple (a) Collection in Khang (b) Transportation by pick up truck (c) Road side marketing shed. 